\title{
Editorial
}

Digestion

Published online: November 6, 2007

\section{Open-Access Upper GI Endoscopy in the 21st Century}

\author{
Mattijs E. Numans \\ Julius Center for Health Sciences and Primary Care, University Medical Center Utrecht, Utrecht, The Netherlands
}

Primary health care in many parts of Western Europe has evolved over the past 30 years. More and more casedriven 'surgery hours' by single-handed physicians have been replaced by well-organized, evidence-based working, multidisciplinary group practices. Well-educated 'specialized' general practitioners (GPs), aware of their crucial position in health care, are taking care of $90 \%$ of the questions presented in primary care. GPs serve as well-recognized and respected gate-keepers and health consultants for many patients trying to find their way through increasingly complicated health care in many countries. Primary care-oriented guidelines have been developed in many clinical fields and nowadays GPs often develop these guidelines together with consultants and specialists.

Primary care gastroenterology has evolved together with these developments. As soon as adequate and safe acid-reducing medication became available, primary care physicians were prescribing it because empirical treatment worked. While discussion focused on potential postponement of the diagnosis of malignancy caused by uncontrolled use of H2RA or PPI in primary care, openaccess endoscopy was developed primarily in the UK by the end of the 1970s [1]. Although the first experiments mainly reported an increase in the amount of endoscopies not justified by the relevance of pathology found, quality of referrals slowly improved partly due to involvement of a group of GPs educated and licensed to perform diagnostic endoscopies in hospitals [2]. These examples inspired GPs in the Netherlands and other countries to establish open access to especially upper GI endoscopy without referring patients to secondary care.

Our Dutch experience with open-access endoscopy in the 1980s showed that the increase in endoscopies is a more or less autonomous process, taking place in primary as well as in secondary care. Although one would hypothesize that open-access upper GI endoscopy would mainly be used to exclude malignancy, open-access endoscopies appeared to show relatively more often diseases that can be treated in primary care too $[3,4]$. As shown by van Kerkhoven et al. [this issue], developments in upper GI symptom management and treatment over the following decade caused changes in endoscopic findings that are in line with expectations. New developments like empirical (short-term) treatment with PPI and Helicobacter pylori eradication have reduced peptic ulcers and the relative amount of GERD-related abnormalities has increased by eliminating $H$. pylori-related peptic ulcers and functional disease before endoscopy is performed.

From a primary care perspective open-access upper GI endoscopy would mainly be used to exclude malignancy in patients with persisting or presumed alarming symptoms or in patients otherwise at risk for developing malignancy. Ideally adequate referral for endoscopy from primary care thus would lead to an increase in early diagnosis of malignancy as well as to a relatively large group of patients adequately reassured that their symptoms are of a benign origin. However, alarm symptoms do only

\section{KARGER}

Fax +4161306 1234

E-Mail karger@karger.ch

www.karger.com
(C) 2007 S. Karger AG, Basel

0012-2823/07/0754-0225\$23.50/0

Accessible online at:

www.karger.com/dig
Mattijs E. Numans, MD, PhD

Julius Center for Health Sciences and Primary Care

University Medical Center Utrecht

NL-3508 Utrecht (The Netherlands) 
partly predict malignancy and can hardly be used to set a proper indication for upper GI endoscopy [5]. Research into the early diagnosis of upper GI malignancy by 'rapid' access endoscopy has not been very rewarding in the Western population [6]. In spite of this an increasingly demanding population seems only to want to be reassured by benign results of high-tech investigational methods. So in order to keep health care budgets and endoscopy departments protected from inadequate overuse, further efforts need to be made to help especially primary care physicians to select the proper category of patients to investigate in their process of reducing the risk of miss- ing a serious disease in a treatable stage. Further research into diagnostic determinants of relevant findings in upper GI endoscopy should be founded in the primary care population. And the next challenge will be to implement study results into daily practice. Cooperation of primary and secondary care physicians and researchers is essential to make this possible. An innovative group of 'GPs with specialist interests' as developing among GPs in the UK and the Netherlands, providing for primary care-oriented GI knowledge, might facilitate the bridge between primary and secondary care to further improve the use of open-access endoscopy facilities [7].

\section{References}

1 Holdstock G, Wiseman M, Loehry CA: Open-access endoscopy service for general practitioners. Br Med J 1979;i:457-459.

2 Hungin AS: Use of an open-access gastroscopy service by a general practice: findings and subsequent specialist referral rate. J R Coll Gen Pract 1987;37:170-171.

3 Wit NJ, Numans ME, van der Graaf Y, de Melker RA: Upper GI endoscopy initiated by the family physician; evaluation of an open access service in the Netherlands. Gastroenterology 1999;116:abstr G0449.
4 Numans ME, Van der Graaf Y, de Wit NJ, Touw-Otten F, de Melker RA: How much ulcer is ulcer-like? Diagnostic determinants of peptic ulcer in open access gastroscopy. Fam Pract 1994;11:382-388.

5 Meineche-Schmidt V, Jorgensen T: 'Alarm symptoms' in patients with dyspepsia: a three-year prospective study from general practice. Scand J Gastroenterol 2002;37: 999-1007.
6 Paterson HM, McCole D, Auld CD: Impact of open-access endoscopy on detection of early oesophageal and gastric cancer 19942003: population-based study. Endoscopy 2006;38:503-507.

7 Jones RH, Numans ME: The primary/secondary care interface in gastroenterology. Eur J Gen Pract 2004;10:78-79. 